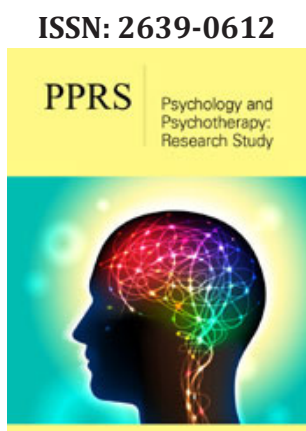

*Corresponding author: Anatoliy V Kharkhurin, Department of Psychology, HSE University, Russia

Submission: 侮 October 05, 2020

Published: 䟧 October 22, 2020

Volume 4 - Issue 3

How to cite this article: Anatoliy V Kharkhurin, Agniya Pasechnik. Plurilingual Intercultural Creative Keys: Updated Educational Program. Psychol Psychother Res Stud. 4(3). PPRS. 000586. 2020 DOI: 10.31031/PPRS.2020.04.000586

Copyright@ Anatoliy V Kharkhurin, This article is distributed under the terms of the Creative Commons Attribution 4.0 International License, which permits unrestricted use and redistribution provided that the original author and source are credited.

\section{Plurilingual Intercultural Creative Keys: Updated Educational Program}

\author{
Anatoliy V Kharkhurin* and Agniya Pasechnik \\ Department of Psychology, HSE University, Russia
}

\begin{abstract}
This article presents a brief overview of an updated Plurilingual Intercultural Creative Keys (PICK) educational program. The program suggests modifications to existing curricula to adjust it to the current realia by promoting plurilingualism, interculturalism and creativity in early schooling. The program has five distinct goals, each of which contributes to non-invasive modifications of the school curriculum: to foster students' creative potential; to promote multilingual competence; to nurture intercultural competence; to encourage intrinsic motivation; and to establish a positive psychological climate. To accomplish these goals, the program utilizes a holistic approach that constitutes five categories of methods and techniques, which focus on the psychological climate in the classroom, encourage students enthusiastic attitude toward schooling, facilitate students' curiosity, develop intercultural competence, and utilize an action-oriented approach.
\end{abstract}

Keywords: Plurilingualism; Multilingualism; Creativity; Intercultural competence; Plurilingual education; Creative education; Pedagogy

Abbreviations: PICK: Plurilingual Intercultural Creative Keys

\section{Introduction}

The academic community recently revealed interest in exploring the potential links between the use of multiple languages and creativity [1-5]. However, the benefits of merging programs fostering creative capacities and plurilingual abilities continue to escape the attention of educators [6]. It is evident that creativity-fostering programs operate separately from those offering (multiple) language development. The researchers and teachers in the two fields have mutually exclusive training, being educated in either creativity or language related disciplines, but not in both. Moreover, programs offering multilingual teaching, in the best traditions of bi-/multilingualism approach [7,8], tend to neglect the importance of nurturing intercultural competence. At the same time, the latter appears to be an integral part of experience with multiple languages [9] and the concept of plurilingual and intercultural education is promoted at least in theory in Europe $[10,11]$. The potential efficacy of a program combining the use of multiple languages, interculturality and creativity can be directly inferred from the empirical findings and theoretical considerations advanced over the last 15 years. Various factors in plurilingual individuals' development were demonstrated to facilitate certain cognitive mechanisms and personality traits underlying their creative capacities [12]. These studies present a case for a relationship between linguistic, cultural, and creative competences. Evidently, these competences can be nurtured through education. Kharkhurin $[6,13]$ proposed a Bilingual Creative Education program, which constituted a unified teaching model introducing both language learning and creativity-fostering instruction to the school curriculum. However, as a result of expansion of the theoretical framework [14], the goals of the program were modified to address not only linguistic, but also intercultural aspects of language acquisition and use. Therefore, the program was renewed under a new name Plurilingual Intercultural Creative Keys (PICK) as in fact it was informed by a series of the features that characterize the plurilingual perspective Coste D, Moore D, Zarate G (1997/2009) Plurilingual and pluricultural competence. Council of Europe, Language Policy Division. Strasbourg, FR.

The modified version of the program has five distinct goals, each of which contributes to non-invasive modifications of the school curriculum. First, it aims to foster students' creative 
potential. The focus of the program is not on bigger-C eminent creative achievements, but on the smaller-c creative capacities [15] that are grounded in mundane cognitive functioning and can be applied to everyday problem-solving. Second, it aims to promote multilingual competence. It employs dual language strategies (also known as two-way immersion programs; Calderón [16], in which through content instruction, students learn foreign languages while maintaining and developing their native tongue. Third, it strives to nurture intercultural competence [17] in a diversity of student populations. This program is designed not only for migrants who speak their native language and who are attempting to acquire the language of the country to which they have migrated. It is conceived for all students, immigrants as well as those who want to acquire a new language. By combining students with diverse linguistic and cultural backgrounds, the program promotes linguistic and ethnic equity among the children and teaches them intercultural awareness. The latter appears to be a valuable attitude in the multicultural context, which emphasizes tolerance towards individuals of different linguistic, cultural, ethnic, or religious backgrounds. Fourth, the program strives to encourage both teachers' and students' intrinsic motivation, which appears to be an invaluable trait in language learning, creative performance, and overall schooling. Finally, the program promotes establishing a psychological climate constructive to learning. It aims at building a closer bond between teachers and students and raising students' awareness of their own feelings and the environment.

To accomplish these goals, the program utilizes a holistic approach that combines cognitive, personal, and sociocultural factors. This approach considers not only educational aspects directly pertinent to the school curriculum, but also those reflecting a student's personality and sociocultural environment. Thus, the rationale is not to establish a special program focusing on children with exceptional abilities, but to suggest modifications to existing curricula and/or the classroom environment in order to promote plurilingualism, interculturalism and creativity in early schooling.

The outcomes of such a program do not reflect the ambitious aspirations of nurturing eminent individuals (although, this perspective should not be excluded). Thereby, it disqualifies an elitist view and provides opportunities to enhance the overall plurilingual, intercultural, and creative competences of all students regardless of their sociocultural background and intellectual predispositions. This constitutes an important characteristic of the program, its scope of application. The program can be implemented in any school curriculum, depending on the specific details of a given school. The role of the program coordinator would be to modify the core of the program to reflect the specificity of the student body and the sociocultural, economic, and political environment of each particular school. The idea is to convert any curriculum into one fostering plurilingual and intercultural competences as well as creative potential. Thereby, it reflects the EU recommendation to its Member States, that methodologies should be developed to modify and improve the effectiveness of existing educational programs $[18,19]$. Moreover, these modifications can be accomplished at a low cost because they would not require major restructuring of existing school curricula.

Currently, the program is employed by Gazprom school in Russia. The pilot study of the program runs for 12 months. The program is delivered by bilingual teachers fluent in both English and Russian. The teachers underwent special PICK training, which consists of a weeklong series of lectures, seminars, and masterclasses. The purpose of the training was to adjust teachers' perception of the educational process and to equip them with knowledge and skills to establish a constructive psychological climate in the classroom, encourage enthusiasm and curiosity in students and deliver the program in a manner fostering their linguistic and intercultural competencies and creative capacities. The program constitutes 5 categories of methods and techniques; we call them PICK dimensions. Individual items from each dimension can be used sequentially or simultaneously throughout the entire schooling process. That is, as a result of the PICK training teachers became competent enough to decide themselves when and how it is appropriate to use them.

The first dimension focuses on the psychological climate in the classroom. The techniques presented in this dimension encourage a teacher to develop student-centered attitude, to actively manipulate classroom settings and to employ relaxed alertness techniques. The second dimension encourages students' enthusiastic attitude toward schooling. The foremost aspect of this process for a teacher is to become a role model for students, because enthusiasm of the former appears to to stimulate for the latter. These techniques can be successfully combined with those encouraging positive peer pressure. Further, a teacher employs various techniques to maintain students' focused attention, to stimulate their independence and open-mindedness, and to highlight relevance of the subject to students' life. The third dimension intends to facilitate students' curiosity, which appears to be a crucial element of the program, because these techniques help the students to acquire the sense of purpose and intention of the educational process and to deepen into the taught material. These techniques teach students to initiate new projects, to incubate new ideas, to come up with critical-thinking questions, etc. The fourth dimension deals with the core element of the program, the intercultural competence. The techniques collected in this dimension intend to facilitate cultural awareness, build intercultural communication skills, articulate emotional intelligence traits, and stimulate creative personality traits. These skills become paramount in the contemporary world witnessing gradually increasing interactions between different nations, which in turn become intrinsically intercultural. The fifth dimension implements an action-oriented approach, which encourages students to realize individual and group projects. This approach is driven by a range of (creative) thinking techniques and teaches students important skills such as creative perception, goal orientation, and boldness. It also incorporates a range of techniques encouraging acquisition and use of multiple languages. To ensure full linguistic immersion, the instructions and teaching materials are given in both languages interchangeably, both in oral (in-class) 
and written (homework) modalities.

We expect that the PICK teaching strategies a) improve an overall schooling process, b) foster students' creative potential, c) enhance students' linguistic abilities, and d) improve their intercultural competence. The first goal is accomplished by using material studied in the core curriculum. Students in the PICK program deal with the same material they have already studied, but in a more elaborate and game-like manner. This improves their understanding and retention of the material, which eventually results in better school performance. The second goal is accomplished by intensive use of creativity fostering techniques. The third goal is accomplished by increasing students' motivation to use both languages in the academic environment. Motivation was shown to play a crucial role in both successful language learning and prolific creative behavior. In the PICK class, the students learn to use both languages in solving interesting and game-like problems. In turn, this increases their motivation to improve their linguistic skills. The fourth goal is accomplished by bringing culture specific perspectives corresponding to both languages. Students learn to tolerate different, often contradicting traditions, values, and norms.

To assess the program's success, we designed a system of students' performance assessment. Note that the assessment aims not to evaluate or judge students' accomplishments. Rather, it aims to monitor students' performance in order to supply the empirical data for the program. This incentive requires more authentic assessment tools and scoring rubrics. The PICK identifies four groups of assessment that serve the following purposes: identification, placement, progress, and achievement. The identification assessment was administered in the form of surveys when students registered at the program. This assessment collected general information about students' cultural and linguistic background and their creative and intercultural attitudes. The placement assessment determines students' creative potential and mastery in both languages. The progress assessment is an ongoing evaluation that intends to monitor students' multilingual, intercultural, cognitive, and creative development as they progress through the program. This assessment is administered every two months. The achievement assessment is used to identify whether students' outcomes satisfy linguistic, creative and academic expectations. This assessment will be administered at the end of the project. The results of the project will follow.

\section{Acknowledgement}

This study was supported by the Faculty of Social Sciences, HSE University.

\section{References}

1. Furlong A (2009) The relation of plurilingualism/culturalism to creativity: A matter of perception. International Journal of Multilingualism 6(4): 343-368.
2. Fürst G, Grin F (2018) Multilingualism and creativity: A multivariate approach. Journal of Multilingual and Multicultural Development 39(4): 341-355.

3. Leikin M, Tovli E (2014) Bilingualism and creativity in early childhood. Creativity Research Journal 26(4): 411-417.

4. Piccardo E (2017) Plurilingualism as a catalyst for creativity in superdiverse societies: A systematic analysis. Front Psychol 8(2169): $1-13$.

5. Storme M, Celik P, Camargo A, Forthmann B, Holling H, et al. (2017) The effect of forced language switching during divergent thinking: A study on bilinguals; Originality of ideas. Frontier in Psychology 8(2086).

6. Kharkhurin AV (2012) Multilingualism and creativity. Multilingual Matters, Bristol, UK.

7. Gogolin I (1994) Der monolinguale habitus der multilingualen schule. Münster: Waxmann, Germany.

8. Gogolin I (2002) Linguistic and cultural diversity in Europe: A challenge for educational research and practice. European Educational Research Journal 1(1): 123-138.

9. Council of Europe (2018) Common European framework of reference for languages: learning, teaching, assessment. Council of Europe, Strasbourg, France.

10. Beacco JC, Byram M, Cavalli M, Coste D, Cuenat ME, et al. (2016) Guide for the development and implementation of curricula for plurilingual and intercultural education. Council of Europe, Strasbourg, France.

11. Candelier M, Grima C, Candelier A, Castellotti M, De Pietro A, et al. (2013) FREPA-A framework of reference for pluralistic approaches to languages and cultures: Competences and resources. Council of Europe, Strasbourg, France.

12. Kharkhurin AV (2018) Bilingualism and creativity. In: Altarriba J, Heredia RR (Eds.) An Introduction to Bilingualism: principles and processes, $\left(2^{\text {nd }}\right.$ edn), Psychology Press, New York, USA, pp. 159-189.

13. Kharkhurin AV (2016) Introducing bilingual creative education to the Russian school curriculum. RUDN Journal of Psychology and Pedagogics 4: 16-28.

14. Kharkhurin AV (in print) Plurilingual creativity: A new framework for research in multilingual and creative practices. In: Piccardo E, Rutherford GA, Lawrence G (Eds.), Routledge Handbook of Plurilingual Language Education, UK.

15. Kaufman JC, Beghetto RA (2009) Beyond big and little: The four-c model of creativity. Review of General Psychology 13(1): 1-12.

16. Calderón ME, Rowe ML (2003) Designing and implementing two-way bilingual programs: A step-by-step guide for administrators, teachers and parents. Corwin Press, Thousand Oaks, CA USA.

17. Griffith RL, Wolfeld L, Armon BK, Rios J, Liu OL (2016) Assessing intercultural competence in higher education: Existing research and future directions. ETS Research Report Series 2016(2): 1-44.

18. Commission of European Communities (2008) Improving competences for the 21 $1^{\text {st }}$ century: An agenda for European cooperation on schools. Communication from the Commission to the European Parliament, the Council, the European Economic and Social Committee and the Committee of the Regions. Brussels, Belgium.

19. Marsh D, Hill R (2009) Study on the Contribution of multilingualism to creativity. Final Report: European Commission. 